Leser der MMW können sich mit allen Fragen zur Abrechnung und Praxisführung an Helmut Walbert, Facharzt für Allgemeinmedizin, Würzburg, wenden. Sie erreichen inn jeden Donnerstag von 13 bis 15 Uhr unter der kostenlosen Rufnummer (0800) 2379830 oder per E-Mail: w@lbert.info.

Helmut Walbert

Allgemeinarzt, Medizinjournalist und Betriebswirt Medizin

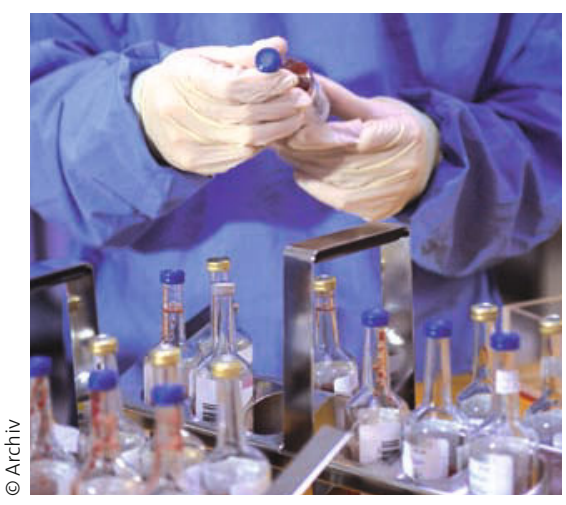

Abrechnung von Laborleistungen: PKV macht Probleme.

Frage von Dr. med. F. L., Urologe, Köln: Bei einem Privatpatienten hat der private Krankenversicherer die von mir abgerechneten O-III-Leistungen - im konkreten Fall $\mathrm{TSH}, \mathrm{T}_{3}, \mathrm{~T}_{4}$ - nicht erstattet. Dem Patienten gegenüber erfolgte der Hinweis, mir fehle die Abrechnungsberechtigung. Ich beziehe diese Laborleistungen wie im GKV-Bereich über unsere Laborgemeinschaft. Was kann ich machen?

\title{
O-III-Leistungen
}

\section{Fehlt mir wirklich die Abrechnungsberechtigung?}

Antwort: Es ist offensichtlich, dass auch private Krankenversicherer (PKV) die Abrechnung der Niedergelassenen immer intensiver kontrollieren. Nicht immer sind die Einsprüche der PKV berechtigt.

Im Gegensatz zur GKV, wo es akzeptiert ist, dass die von Ihnen zitierten Laborleistungen auch in der Laborgemeinschaft erbracht werden dürfen, beziehen sich die privaten Krankenversicherer auf die Regeln der GOÄ. Diese fordern bei O-III-Leistungen erstens die Qualifikation zur Erbringung und Interpretation. Dies wird gegebenenfalls durch die Weiterbildungsordnung definiert. In diesem Zusammenhang sind Sie durchaus berechtigt, bei Abklärung der hormonellen Situation eines Patienten auch die Schilddrüse zu überprüfen und zu beurteilen.

Zum zweiten aber fordert die GOÄ die persönliche Leistungserbringung. Im konkreten Fall heißt dies: auch bei Qualifikationsvoraussetzung muss die Laborleistung unter Ihrer Aufsicht erbracht werden in Ihrem Labor oder in einem Gemeinschaftslabor, das nachweislich unter Ihrer Aufsicht steht. Auf diese Voraussetzungen beruft sich die PKV. In Ihrem konkreten Fall muss also eine Rechnungsstellung durch den Laborarzt erfolgen. Diese kann entweder direkt an den Patienten gehen oder wird über Sie an den Patienten weitergereicht. Dann ist die PKV erstattungspflichtig.

\section{Privatpatient}

\section{Muss ich den Basistarif akzeptieren?}

Frage von Frau Dr. med. H. L., Allgemeinärztin, Dresden:

Ein neuer Patient stellte sich bei mir vor und gab an, dass er privat versichert sei zum Basistarif. Muss ich den Basistarif akzeptieren?

Antwort: Leider ja. Mit Wirkung zum 1. April 2010 wurde zwischen der KBV, der Privaten Krankenversicherung (PKV) und der Beihilfe eine vertragliche Vereinba- rung geschlossenen aufgrund derer Sie bei einem Basistarifpatienten nach abgesenkten festen Sätzen der GOÄ behandeln müssen!

Leistungen des Abschnitts $M$ (Labor) der GOÄ werden mit dem o,9-fachen des Gebührensatzes der GOÄ vergütet, Leistungen der Abschnitte A (Gebühren in besonderen Fällen), z.B. GOP 2 und 56, GOP 250 und 250a, sowie technische Leistungen wie Spirometrie und EKG sowie weitere GOP werden mit dem 1,0-fachen des Gebührensatzes der GOÄ vergütet, die übrigen vor allem ärztlichen Leistungen der GOÄ mit dem 1,2-fachen Satz. Wenn Sie den Behandlungsvertrag eingehen, sind Sie als Vertragsärztin zur Behandlung zu diesen Sätzen verpflichtet. Weiterhin hat sich die KBV der PKV gegenüber verpflichtet, uns anzuhalten, diese Patientengruppe streng nach den Wirtschaftlichkeitsmaßstäben der GKV zu behandeln. 